\title{
Antioxidant and Anti-fatigue Activities of Seed Oil from the Berries of Three Indigenous Plants in Tibetan Plateau
}

\author{
Lijuan Han ${ }^{1,2}$, Jing Meng ${ }^{1,2}$, Yongjing Yang ${ }^{1,2}$, Ying Ye ${ }^{1,2}$, Yourui Suo ${ }^{1,3, *}$ \\ ${ }^{1}$ Key Laboratory of Tibetan Medicine Research, Northwest Institute of Plateau Biology, Chinese Academy of Sciences, Xining, China \\ ${ }^{2}$ University of the Chinese Academy of Sciences, Beijing, China \\ ${ }^{3}$ Qinghai Academy of Agriculture and Forestry Sciences, Xining, China \\ *Corresponding author: yrsuo@nwipb.cas.cn
}

Received July 30, 2015; Revised August 28, 2015; Accepted September 09, 2015

\begin{abstract}
The edible berries of three plants indigenous to the Tibetan plateau, namely Nitraria tangurorum B. (NTB), Hippophae rhamnoides L. (HRL) and Berberis dasystachya M. (BDM), have been used for medicinal purposes for a long time. For these three berries that occur in the wild, it is important to understand the differences between the content and biological activity of their seed oils. Therefore, this study was designed in order to determine the total polyphenol content (TPC), carotenoid content (TCC), steroid content (TSC) and fatty acid composition of seed oils obtained from these three berries, using standard analytical methods. In addition, in vivo anti-fatigue activity of three seed oils were investigated using forced swimming mice. Free radical scavenging activity and antioxidant capacity were estimated using different assays. The results indicated that seed oil of these three berries contained a variety of active compounds. BDM seed oil showed a higher TPC concentration of 281.61 $\pm 19.06 \mu \mathrm{g} / \mathrm{g}$ compared to the other berries; HRL seed oil showed a higher TSC concentration of $329.06 \pm 16.53$ $\mu \mathrm{g} / \mathrm{g}$ compared to the other berries. The total content of polyunsaturated fatty acids in seed oils from the three berries was found to be 331.6, 342.91 and $305.39 \mu \mathrm{g} / \mathrm{mL}$ for NBT, HRL, and BDM, respectively. The antioxidant assay results indicated that the seed oil obtained from HRL was significantly more active in scavenging free radicals compared to the other seed oils. Therefore, the results indicate that such seed oil supplements could prevent lipid oxidation in forced swimming mice.
\end{abstract}

Keywords: Nitraria tangurorum B., Hippophae rhamnoides L., Berberis dasystachya M., seed oil, antioxidant, anti-fatigue

Cite This Article: Lijuan Han, Jing Meng, Yongjing Yang, Ying Ye, and Yourui Suo, "Antioxidant and Antifatigue Activities of Seed Oil from the Berries of Three Indigenous Plants in Tibetan Plateau." Journal of Food and Nutrition Research, vol. 3, no. 7 (2015): 445-457. doi: 10.12691/jfnr-3-7-6.

\section{Introduction}

Fatigue, depending on its origin, can be classified as physical (caused by excessive exercise) or mental (caused by sleep deprivation) [1]. Physical fatigue is an important factor affecting bodily performance, and often leads to premature aging, cancer, depression and other underlying physical disorders [2]. In recent years, researchers' efforts have mainly focused on several factors contributing to physical fatigue such as the consumption of energy sources [3], accumulation of metabolic products [4], and production of reactive oxygen species (ROS) [5,6]. The concept of swimming to exhaustion is an experimental model used to evaluate anti-fatigue [3]. Anti-oxidant compounds such as polyunsaturated fatty acids (PUFA), polyphenols, and carotenoids, are known to exhibit a protective activity against various chronic diseases that are caused by ROS [7,8,9].

Three indigenous medicinal fruits that grow in the Tibetan plateau have been studied: Nitraria tangurorum B.
(White-thorn), Hippophae rhamnoides L. (Black-thorn), and Berberis dasystachya M. (Yellow-thorn). All three plants are collectively referred to as the 'three thorns'. The berries of the three thorns have been eaten and used for medicinal purposes for centuries [10]. The plants or plant derived products seem to possess moderate efficacy with either no toxicity, or a lower toxicity, than synthetic drugs, making them attractive candidates for drug development research programs. Since the 1980's, the berries from the three thorns have been processed and marketed. Two such products are 'The Cream of Three Thorn' and 'The Three Thorn Juice'. It is known that these three berries contain a large amount of bioactive compounds, including phytosterols, organic acids, carotenoids, and polyphenols [11,12]. In traditional Tibetan medicine, a variety of native plants and their berries were used to alleviate fatigue caused by oxygen deficiency [13]. Research studies have shown that the seed oil extracted by solvent solution from N.tangurorum [14], and the water-extracted compound of $\mathrm{H}$. rhamnoides exhibit anti-fatigue activity [15]. The seed oils extracted with organic solvents from $N$. 
tangurorum and $H$. rhamnoides have been shown to contain polyunsaturated fatty acids ( $N$. tangurorum $92.27 \%$ of total fatty acid content; $H$. rhamnoides $88.40 \%$ of total fatty acid content [16]. Studies on the active phyto-chemicals present in seed oil of $B$. dasystachya Maxim, lacked characterization analysis and investigation of the pharmacological activities. The popularized three berries are high-quality medicinal and edible berries occurring indigenously in the Tibetan plateau. However, it is not known whether there are significant differences in the seed oil content and biological activity between the three berries.

In the majority of investigations to date, the seed oils were extracted with organic solvents. Instead, continuous mechanical expression (screw pressing) is used to extract natural products intended for use as food or pharmaceutical products [17]. Compared to conventional extraction with organic solvents, screw press expression possesses many advantages as it is non-toxic, costefficient, and has a lower-process temperature. Thus, it meets the growing requirements of the market for wholly 'natural' products [18]. However, to the best of our knowledge, the composition, antioxidant properties, and anti-fatigue effects of seed oils obtained by screw pressing from the three thorns have not been compared before. The main objective of this study is to analyze and compare the phyto-chemical composition of seed oils obtained by screw press expression from Nitraria tangurorum B., Hippophae rhamnoides L., and Berberis dasystachya M., evaluate the in vitro effects of the seed oils on free radical scavenging and to investigate any relevant anti-fatigue effect on forced swimming mice.

\section{Materials and Methods}

\subsection{Materials}

The berries of Nitraria tangurorum B., Hippophae rhamnoides L., Berberis dasystachya M. were collected from Dulan town (N 36.321, E 98.111; altitude: $3100 \mathrm{~m}$ ), Tianjun town (N 39.23, E 97.54; altitude: $3600 \mathrm{~m}$ ), MenYuan town (N 37.52, E 102.21; altitude: 3400 m), Haixi national municipality of Mongo land Tibetan, Qinghai, China. Freshly collected specimens were identified by Prof. Xuefeng Lu, Northwest Plateau Institute of Biology, Chinese Academy of Sciences in Xining, China. The herbarium samples were numbered as NT20140910 for Nitraria tangurorum B.(the species was consistant with $\mathrm{Ni}$ et.al [18], NO. NT20110802), HR20140823 for Hippophae rhamnoides L. (the species was consistant with Ni et.al [18], NO. HR20110805) and BD20140826 for Berberis dasystachya M., and deposited at Qinghai Key Laboratory of Tibetan Medicine Research. The seeds were separated from the berries and the moisture content of three seeds was lowered to about 5\% (db) by air-drying in the vacuum oven.

\subsection{Preparation of Seed Oil}

Oil expression was carried out using a screw press (S60model, WanLong Machinery, China). The preparation conditions were as follows: the screw rotation speed was set to $64 \mathrm{rpm} / \mathrm{min}$, the preheating temperature of the screw head was $120^{\circ} \mathrm{C}$ and the screw time was $45 \mathrm{~min}$. The crude oil was then centrifuged (10 $\mathrm{min}, 3,000 \mathrm{rpm} / \mathrm{min}$, at room temperature) to separate the oil out [19]. Oil extraction yield was defined as the ratio of oil extracted from screw press, to the amount of oil originally present in the seeds. The seed oil of the three berries were stored at $20^{\circ} \mathrm{C}$ for further use.

\subsection{Determination of Phyto-chemical Composition of Oil}

FTIR spectrometer (Bruker Tensor 27) was used during the FIR spectra acquisition. A FTIR spectrum of the sample was determined in the frequency range of 4000$400 \mathrm{~cm}^{-1}$.

Total polyphenol content (TPC) was estimated using the Folin-Ciocalteu method. The calibration curve was prepared with standard gallic acid at different concentrations [20,21]. The seed oil was extracted with 10 $\mathrm{ml}$ of methanol (80 \%) in an ultrasonic cleaner $(60 \mathrm{~Hz}, 2 \mathrm{~h})$ at room temperature, and then filtrated and the residue was re-extracted with $10 \mathrm{ml}$ of methanol [20]. After filtration, the filtrate was mixed with Folin-Ciocalteu reagent and sodium carbonate. The absorbance of the mixture was then measured at $765 \mathrm{~nm}$ after $1 \mathrm{~h}$. TCC was determined according to the method of Ilyasoğlu [22]. The carotenoid curve was prepared with $\beta$-carotene at different concentrations, and the seed oil was extracted with $10 \mathrm{ml}$ of hexane. The absorbance of the filtrate was then measured at $450 \mathrm{~nm}$. Total Steroid Content (TSC) was determined according to the method of $\mathrm{Li}$ et al. [23]. The steroid curve was prepared with $\beta$-sitosterol at different concentrations. The absorbance of the filtrate was measured at $703 \mathrm{~nm}$.

Gas chromatography-mass spectrometry (GC-MS) was used for analyzing compositions of the fatty acids in seed oil. An Agilent 112-8867 GC-MS was carried out using a HP-88 MS column $\left(60 \mathrm{~m} \times 0.25 \mathrm{~mm} \times 0.25 \mu \mathrm{m}, 250^{\circ} \mathrm{C}\right.$, $\mathrm{He}$ as the carrier gas) with flame ionization detection (FID). The oven temperature program was as follows [24]: the initial temperature of the column was $40^{\circ} \mathrm{C}$, held for 3 $\mathrm{min}$, first, a $40^{\circ} \mathrm{C} / \mathrm{min}$ ramp to $120^{\circ} \mathrm{C}$, and held for $1 \mathrm{~min}$, then an $8^{\circ} \mathrm{C} / \mathrm{min}$ ramp to $160^{\circ} \mathrm{C}$, and held for $10 \mathrm{~min}$, then a $3^{\circ} \mathrm{C} / \mathrm{min}$ ramp to $181^{\circ} \mathrm{C}$, and held for $5 \mathrm{~min}$. Finally, a $2^{\circ} \mathrm{C} / \mathrm{min}$ ramp to $212^{\circ} \mathrm{C}$, and held for $15 \mathrm{~min}$. The carrier gas was helium, which was set at a flow rate of $40 \mathrm{ml} / \mathrm{min}$, the split ratio was 400:1, and the injection quantity was 1 $\mu \mathrm{L}$. The fatty acids of the seed oil were derivatized into methyl esters before GC-MS analysis.

\subsection{Determination of Anti-oxidant Activities in vitro}

\subsubsection{Preparation of Samples}

There are several considerations regarding the methodology to evaluate the antioxidant capacity. Due to the complex nature of seed oils, and taking in consideration the different mechanisms of antioxidant activity, more than one method for measuring antioxidant activity should be employed in order to estimate the total antioxidant capacity. The seed oils were prepared using a method previously described by Lin et al. [25], although with slight modification. The seed oil was obtained by screw press expression (64 rpm/min, $120^{\circ} \mathrm{C}, 45 \mathrm{~min}$ ), then mixed with ethanol/petroleum ether $(1: 1 \mathrm{v} / \mathrm{v})$ to achieve 
several different concentrations $(12.0,10.0,8.0,6.0,4.0$, 2.0 , and $1.0 \mathrm{mg} / \mathrm{mL}$ ). The mixture was then shaken vigorously so that the whole seed oil was dispersed in the solvent. The seed oil solutions were stored at $-20^{\circ} \mathrm{C}$ for further use.

\subsubsection{DPPH Radical Scavenging Activity}

The 2,2-diphenyl-1-picrylhydrazyl radical (DPPH) radical scavenging assay was carried out using the method described by Lin et al. [25], although with a slight modification. Briefly, $1 \mathrm{~mL}$ of the seed oil solution was added into $2 \mathrm{~mL}$ of DPPH solution $(0.2 \mathrm{mM}$ in dehydrated alcohol). The mixture (seed oil mixed with DPPH) was shaken vigorously and incubated in the dark for $30 \mathrm{~min}$ at room temperature, then measured at $517 \mathrm{~nm}$ with a UVvis spectrophotometer (UV759, Shanghai Precision \& Scientific Instrument Co., Ltd, Shanghai, China). The test was replicated three times, and the radical-scavenging activity of the samples was calculated according to equation (1).

$$
\text { Inhibition of DPPH radical }=\left(\frac{\text { Acontrol }- \text { Asample }}{\text { Acontrol }}\right) \times 100 \%
$$

$A_{\text {control }}$ is the absorbance at $517 \mathrm{~nm}$ of the DPPH solution without sample, and $A_{\text {sample }}$ is the absorbance of the DPPH solution with sample.

\subsubsection{ABTS Radical Scavenging Activity}

The 2, 2-azino-bis (3-ethylbenzothiazoline-6-sulfonic acid) diammonium (ABTS) radical scavenging activity was carried out using the method described by DíazReinoso et al. [26], with some modifications. Briefly, 2.45 $\mathrm{mmol} / \mathrm{L}$ potassium persulphate was mixed with $7 \mathrm{mmol} / \mathrm{L}$ aqueous ABTS as the radical solution, and the mixture incubated in the dark at room temperature. The ABTS radical solution was diluted with PBS $(\mathrm{pH}=7.4)$ to an absorbance of $0.70 \pm 0.02$ at $734 \mathrm{~nm}$. The sample solution was mixed with ABTS radical solution at a ratio of 1:20. The mixture of seed oil solution and ABTS was shaken vigorously and incubated in the dark for $6 \mathrm{~min}$ at room temperature, and then the absorbance measured at $734 \mathrm{~nm}$. The test was replicated three times, and the radical scavenging activity of each sample was calculated according to equation (2).

$$
\text { Inhibition of ABTS radical }=\left(\frac{\text { Acontrol }- \text { Asample }}{\text { Acontrol }}\right) \times 100 \%(2)
$$

$A_{\text {control }}$ is the absorbance at $734 \mathrm{~nm}$ of the ABTS solution without sample, and $A_{\text {sample }}$ is the absorbance of the ABTS solution with sample.

\subsubsection{Reduction Assay}

The reduction assay was used according to that previously published by Ferreira et al. [27], with some modifications. Phosphate buffer at a concentration of $0.2 \mathrm{mmol} / \mathrm{L}(\mathrm{pH}=6.6)$ was mixed with $1 \% \mathrm{KOH}$ solution, then $1.0 \mathrm{~mL}$ of the sample mixture was added and incubated in a water bath at $50{ }^{\circ} \mathrm{C}$ for $20 \mathrm{~min}$. After that, $10 \%$ trichloroacetic acid solution was added to the mixture in order to stop the reaction. The mixture was centrifuged at 5,000 rpm for $10 \mathrm{~min}$, and then the supernatant was mixed with $0.1 \%$ ferric chloride solution. The absorbance was measured at $700 \mathrm{~nm}$, as a measure of the reduction capacity.

\subsection{Anti-fatigue Experimental Design}

\subsubsection{Mice and Maintenance}

Healthy male Kunming mice, weighing between $18 \mathrm{~g}$ and 20g, were purchased from the Center of Laboratory Animal of Gan Su University traditional Chinese medicine, Gansu, China. The mice were housed in standard cages $(21.5 \mathrm{~cm} \times 32 \mathrm{~cm} \times 14 \mathrm{~cm}$, five mice per cage) under controlled conditions of temperature $\left(24 \pm 1^{\circ} \mathrm{C}\right)$, humidity (60 $\pm 1 \%$ ). The mice were subjected to $12 / 12 \mathrm{~h} \mathrm{light/dark}$ cycle, and allowed free access to standard rodent food and water during the experiments. Animal handling procedures were conducted under the principles of laboratory animal care and use guidelines [28]. The institution's Animal Ethics Committee reviewed the entire animal protocol, prior to the experiments being conducted. The mice were allowed to adapt to our laboratory housing for at least one week.

\subsubsection{The Forced Swim Test}

The procedure used for the forced swim test (FST) was as previously described by Porsolt et al. [29]. After the last intragastric administration (30 $\mathrm{min}$ ), the mice were placed individually in glass cylinders (height: $35 \mathrm{~cm}$, diameter: $20 \mathrm{~cm}$ ), with a depth of $\geq 30 \mathrm{~cm}$ and with a water temperature of $25 \pm 1^{\circ} \mathrm{C}$. A lead block ( $7 \%$ of their body weight) was loaded on the tail root of each mouse (expect normal group). The mice were considered to be exhausted when they failed to rise to the surface and were struggling to breathe within a $10 \mathrm{~s}$ period. The swimming period was determined as the time spent by the mice swimming or floating in the water until exhaustion, and the swimming period was recorded. The mice were then sacrificed for further examination.

\subsubsection{Mice Treatment}

Mice were trained to adapt themselves to swimming twice (10 min per time) in the first week, and the mice that did not learn to swim were screened out. Mice were randomly divided into the following experimental groups (10 mice/group): the normal control group (NC, $0.8 \%$ physiological saline, and were not subjected to a swimming test), the model control group (MC, $0.8 \%$ physiological saline, and were subjected to a swimming test) and nine experimental groups (different concentration seed oil, and were subjected to a swimming test). The seed oil of NTB, HRL, and BDM were formed into an emulsion and consecutively administered by intragastric administration (at doses of 30, 60 and $120 \mathrm{mg} / \mathrm{kg}$ ), once a day for 21days [30]. The body weights of the mice were observed during initial (day 7), intermediate (day 10) and terminal (day 21) stages of the test.

\subsubsection{Determination of Antioxidant and Anti-fatigue Parameters in Mice}

Mice were anesthetized with an intraperitoneal injection of ketamine (80 mg/kg) and xylazine (4 mg/kg). After administration of the anesthetic, whole blood was immediately withdrawn from the heart in heparinized tubes. The serum was prepared by centrifugation at $4{ }^{\circ} \mathrm{C}$ at 
3,000 $\mathrm{r} / \mathrm{min}$ for $10 \mathrm{~min}$. Levels of glucose (GLU), lactic acid (LC), blood urea nitrogen (BUN), lactic dehydrogenase (LDH) and creatine phosphokinase (CK), were analyzed with commercial kits (GAGO20 Glucose Assay Kit, MAK116 Creatine Kinase Activity Assay Kit, Sigma Alorich, China; A019 Lactic Acid Detection Kit, C013-1 BUN Kit, A020-2 LDH Detection Kit, Nanjing Jiancheng Bioengineering Institute, Nanjing, China).

Liver and muscle were dissected out, then cleaned using normal saline and dried with filter paper. Tissue homogenates were prepared in ice-cold medium $(\mathrm{pH} 7.4$, $10 \mathrm{mM}$ Tris-HCl, $0.1 \mathrm{mM}$ EDTA-2Na, $10 \mathrm{mM}$ Sucrose, $0.8 \% \mathrm{NaCl}$ ) by tissue homogenization, and were centrifuged for $10 \mathrm{~min}$ at $5,000 \mathrm{rpm}$ at $4^{\circ} \mathrm{C}$ to collect the supernatant. The saturated $\mathrm{Na}_{2} \mathrm{SO}_{4}$ solution was added to the supernatant and stirred well. Glycogen was precipitated by adding $5 \mathrm{~mL}$ of ice cold ethanol to the sample mixture and centrifuged at 5,000 rpm for $10 \mathrm{~min}$ at $4^{\circ} \mathrm{C}$. One milliliter of $\mathrm{HCl}(1.2 \mathrm{~N})$ was added to the supernatant $(1: 1 \mathrm{v} / \mathrm{v})$ and incubated at $85^{\circ} \mathrm{C}$ for $2.5 \mathrm{~h}$, then allowed to cool in an ice bath. The hydrolyzed product was evaluated using the DNS method to determine tissue glycogen.

The malondialdehyde (MDA), superoxide dismutase (SOD), glutathione peroxidase (GSH-Px) and catalase (CAT) were evaluated in muscle homogenates and in serum (A003-1 MDA Assay Kit, A001 SOD Assay Kit, A005 GSH-Px Assay Kit, and A007-2 CAT Assay Kit, Nanjing Jiancheng Bioengineering Institute). The protein content was measured using a commercial assay kit purchased from Nanjing Jiancheng Bioengineering Institute and was assayed according to the manufacturer's instruction.

\subsection{Statistical Analysis}

The results were presented as mean values \pm standard deviation and analyzed by Tukey's post hoc test using SPSS version 17.0 software (SPSS, Chicago, IL, USA). The difference was considered significant if $p<0.05$ and highly significant if $p<0.01$.

\section{Results and Discussion}

\subsection{Seed Oil Composition}

The seed oil extract from NTB, HRL, and BDM were further analyzed by FT-IR spectroscopy. As shown in Figure 1, all IR spectra of the seed oils exhibited absorbance bands characteristic of hydroxyl groups (3228 $\sim 3182 \mathrm{~cm}^{-1}$ ), the outer stretching vibration of olefinic C-H groups $\left(3008.78,3009.54,3010.27 \mathrm{~cm}^{-1}\right.$ ) and the symmetric and asymmetric stretching vibrations of aliphatic $\mathrm{CH}_{2}$ groups $\left(2925.43 \sim 2954.60 \mathrm{~cm}^{-1}\right.$ and $2849.32 \sim 2854.67 \mathrm{~cm}^{-1}$ ). The IR spectrum of HRL showed a signal at $3472.08 \mathrm{~cm}^{-1}$ characteristic for the presence of N-H groups in the compounds. The signal of the IR spectrum of $\mathrm{HRL}$ at $2028.93 \mathrm{~cm}^{-1}$ represented a characteristic absorption peak for C-N. All IR spectra of the seed oils showed absorbance bands characteristic of functional groups such as- $\mathrm{CH}_{2}$ (around $\left.1460 \mathrm{~cm}^{-1}\right),-\mathrm{CH}_{3}$ (around $\left.1377 \mathrm{~cm}^{-1}\right)$, and $-\left(\mathrm{CH}_{2}\right)_{\mathrm{n}}-\left(\mathrm{n} \geq 4\right.$, around $\left.718 \mathrm{~cm}^{-1}\right)$. The IR spectrum of BDM displayed signals at 533.60 and $521.91 \mathrm{~cm}^{-1}$ corresponding to characteristic absorption peaks for an enone group.

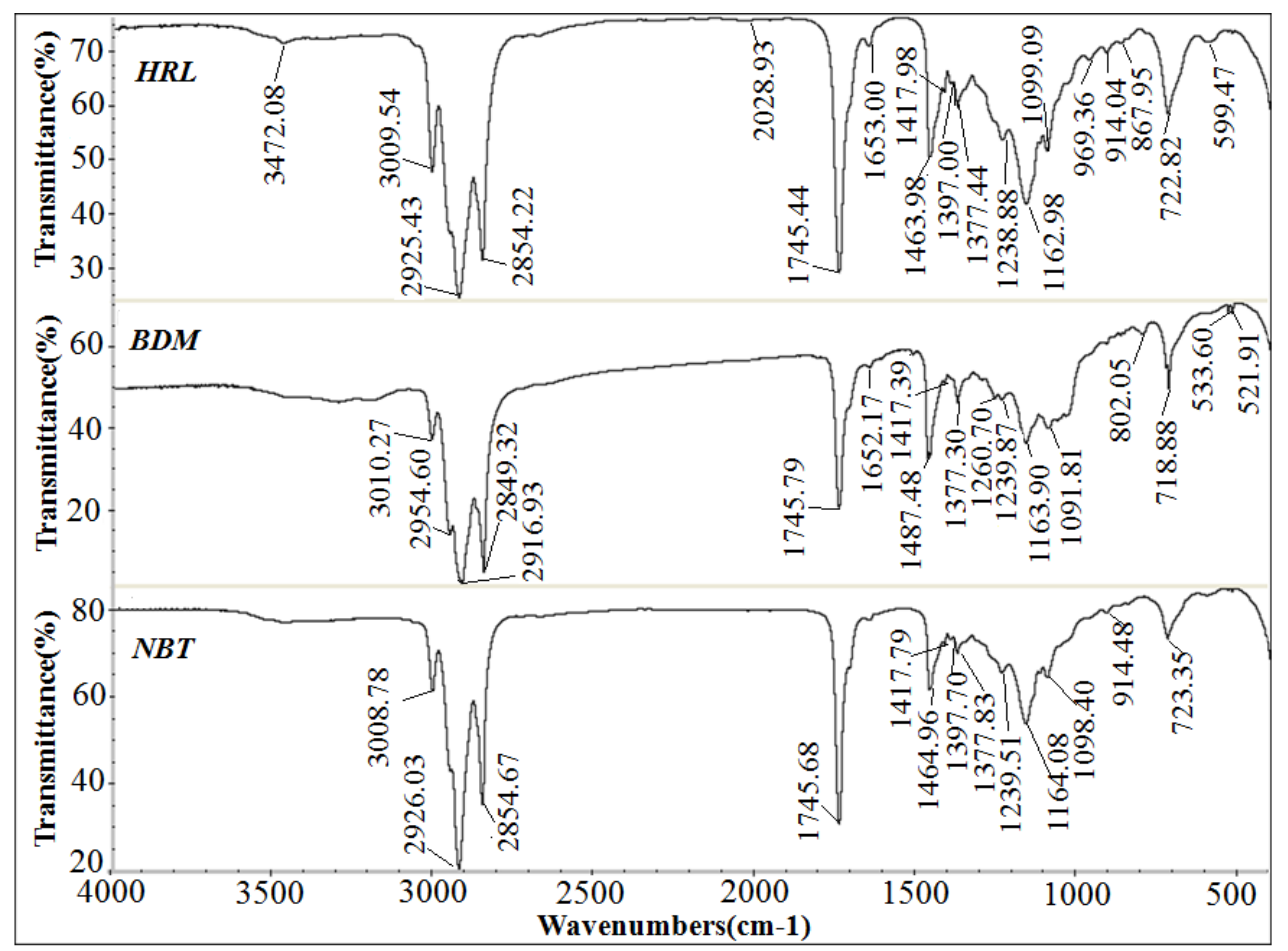

Figure 1. Infrared spectra of seed oils obtained from Nitraria tangurorum B. (NTB), Hippophae rhamnoides L. (HRL), and B. dasystachya M. (BDM)

Note: NTB, seed oil of Nitraria tangurorum B.; HRL, seed oil of Hippophae rhamnoides L.; BDM, seed oil of B. dasystachya M.

The seed oil yield, total polyphenol content (TPC), total carotenoid content (TCC), and total steroids content (TSC) of seed oil in NTB, HRL, and BDM were listed in Table 1. Significant differences in oil yield obtained by screw pressing the three berries could be observed. The HRL exhibited the highest yield with $6.12 \pm 1.56 \%$ obtained, followed by NTB $(5.79 \pm 1.38 \%)$ and BDM (5.32 \pm $1.72 \%)$. Among the seed oils from the three berries, the total polyphenol content (TPC) in BDM (281.61 \pm 19.06 $\mu \mathrm{g} / \mathrm{g}$ ) proved to be the highest, followed by HRL (275.32 
$\pm 28.13 \mu \mathrm{g} / \mathrm{g})$ and NTB $(229.47 \pm 21.91 \mu \mathrm{g} / \mathrm{g})$. The result from the TPC analysis indicated that the seed oil extracted from BDM might exhibit the highest antioxidant activity. Polyphenols have been reported to exhibit a wide range of biological activities. The phenolic compounds are a class of antioxidant agents, which act as free radical scavengers and are considered a major group of compounds that contribute to the antioxidant activities of plant materials. This is predominantly due to the presence of hydroxyl groups that are able to neutralize free radicals [31,32]. Furthermore, the polyphenolic compound extracted from green tea has been found to significantly increase aerobic capacity and to prolong exercise time, possibly due to the antioxidant properties [33].
The carotenoid content of catsup from 13 commercial sources has been directly linked to anti-oxidant activities in vivo and carotenoids are currently being used as natural anti-oxidants [34]. The total carotenoid content of the three seed oils varied from $81.21 \pm 6.79$ to $65.43 \pm 5.46$ $\mu \mathrm{g} / \mathrm{g}$, with the seed oil from HRL displaying the highest total carotenoid content, and BDM the lowest. Accordingly, the TCC results indicated that the seed oil from HRL offered the highest anti-oxidant activity. We also evaluated the total steroid content (TSC). Our results showed that the TSC of HRL $(329.06 \pm 16.53 \mu \mathrm{g} / \mathrm{g})$ proved to be superior to NTB (301.22 $\pm 17.19 \mu \mathrm{g} / \mathrm{g})$ and BDM (291.74 $\pm 22.21 \mu \mathrm{g} / \mathrm{g})$. Lyder et al. [35] indicated that steroids and triterpenoids could also enhance swimming endurance in mice.

Table 1. The yield, TPC, TCC and TSC of seed oils obtained from Nitraria tangurorum B.(NTB), Hippophae rhamnoides L.(HRL), and B. dasystachya M. (BDM)

\begin{tabular}{lllll}
\hline \multirow{2}{*}{ Seed oil } & & \multicolumn{2}{c}{ Composition $(\mu \mathrm{g} / \mathrm{g})$} & \multicolumn{2}{c}{$\begin{array}{l}\text { total carotenoid content } \\
\text { (TCC) }\end{array}$} & $301.22 \pm 17.19$ \\
\cline { 3 - 5 } & Yield(\%) & total polyphenol content (TPC) & $79.13 \pm 5.53$ & $329.06 \pm 16.53$ \\
NTB & $5.79 \pm 1.38$ & $229.47 \pm 21.91$ & $81.21 \pm 6.79$ & $291.74 \pm 22.21$ \\
BDM & $6.21 \pm 1.56$ & $275.32 \pm 28.13$ & $65.43 \pm 5.46$ & total steroids content (TSC) \\
\hline
\end{tabular}

Note: Data are expressed as mean values \pm standard deviations $(\mathrm{n}=5) .{ }^{\mathrm{a}}$ Yield was calculated based on dried seeds mass. NTB, Nitraria tangurorum B.; HRL, Hippophae rhamnoides L.; BDM, B. dasystachya M; TPC, total polyphenol content; TCC, total carotenoid content; TSC, total steroids content.

Oleic and linoleic acids are reported to have good and BDM, respectively. $\gamma$-linolenic acid (GLA) was antioxidant potential [36]. The seed oils of the three berries were derivatized to methylesters and analyzed by GC-MS (Table 2). Six saturated fatty acids (lauricacid, myristic acid, pentadecanoic acid, heptadecylic acid and stearic acid) and six unsaturated fatty acids (palmitoleic acid, oleic acid, linoleic acid, $\boldsymbol{\gamma}$-linolenic acid, $\alpha$-linolenic acid and eicosenoic acid) have been identified. The main saturated fatty acids presented in all three berries were pentadecanoic acid $(65.82 \%$ in NBT, $73.94 \%$ in $\mathrm{HRL}$, $74.24 \%$ in $\mathrm{BDM})$. The ratio of unsaturated to saturated (SFA/UFA) fatty acids is a useful indicator to evaluate nutritional and functional oil characteristics. The SFA/UFA ratio of seed oils obtained from NBT, HRL, and BDM was determined to be $11.79 \%, 8.93 \%$ and $10.38 \%$, respectively. The total content of polyunsaturated fatty acids present in seed oils from the three berries was found to be 331.6, 342.91, 305.39 $\mu \mathrm{g} / \mathrm{mL}$ for NBT, HRL, detected in the seed oil of BDM $(0.58 \pm 0.01 \mu \mathrm{g} / \mathrm{mL})$, the content for the other berries was found to be below the detection limit of the instrument. However, the GLA content of the studied seed oil of HRL and NBT were in good agreement with previously reported values [16]. The seed oil of BDM contained a higher amount of $\alpha$-linolenic acid (ALA, $170.59 \pm 9.63 \mu \mathrm{g} / \mathrm{mL}$ ), indicating that the seed oil from BDM provides a good source for $\alpha$-linolenic acid, a prominent fatty acid that has attracted much attention in recent years [37]. It must be noted that the UFA and PUFA contents from BDM seed oil were lower than in NTB and HRL seed oils. Moreover, the HRL seed oil revealed a higher level of PUFA than NTB, a finding that was not in agreement with the results obtained by Zhang et al. [16]. However, the differences observed between NTB and HRL might be due to environmental conditions such as sampling at different altitudes.

Table 2.The fatty acid composition of seed oil obtained from Nitraria tangurorum B. (NTB), Hippophae rhamnoides L.(HRL), and B. dasystachya M. (BDM)

\begin{tabular}{|c|c|c|c|c|c|c|}
\hline \multirow{2}{*}{ Peak No. } & \multirow[t]{2}{*}{ Compound } & \multirow[t]{2}{*}{ Molecular formula } & \multirow[t]{2}{*}{ Retention time(min) } & \multicolumn{3}{|c|}{ Composition $(\mu \mathrm{g} / \mathrm{mL})$} \\
\hline & & & & NTB & HRL & BDM \\
\hline 1 & Lauricacid(C12:0) & $\mathrm{C}_{12} \mathrm{H}_{24} \mathrm{O}_{2}$ & 10.876 & ND & $\mathrm{ND}$ & $0.138 \pm 0.002$ \\
\hline 2 & Myristic acid (C14:0) & $\mathrm{C}_{14} \mathrm{H}_{28} \mathrm{O}_{2}$ & 12.831 & $0.38 \pm 0.01$ & $0.48 \pm 0.02$ & $0.79 \pm 0.03$ \\
\hline 3 & Pentadecanoic acid(C15:0) & $\mathrm{C}_{15} \mathrm{H}_{30} \mathrm{O}_{2}$ & 14.046 & ND & $0.42 \pm 0.02$ & ND \\
\hline 4 & Palmitic acid (C16:0) & $\mathrm{C}_{16} \mathrm{H}_{32} \mathrm{O}_{2}$ & 15.318 & $24.69 \pm 0.34$ & $41.86 \pm 0.79$ & $26.35 \pm 0.23$ \\
\hline 5 & Heptadecylic acid (C17:0) & $\mathrm{C}_{17} \mathrm{H}_{34} \mathrm{O}_{2}$ & 16.760 & $0.28 \pm 0.02$ & $0.24 \pm 0.01$ & $0.27 \pm 0.02$ \\
\hline 6 & Stearic acid (C18:0) & $\mathrm{C}_{18} \mathrm{H}_{36} \mathrm{O}_{2}$ & 18.343 & $12.16 \pm 0.37$ & $13.61 \pm 0.84$ & $7.95 \pm 0.41$ \\
\hline 8 & Oleic acid (C18:1) & $\mathrm{C}_{18} \mathrm{H}_{34} \mathrm{O}_{2}$ & 19.158 & $110.01 \pm 5.79$ & $115.21 \pm 7.94$ & $62.92 \pm 4.40$ \\
\hline 9 & Linoleic acid (C18:2) & $\mathrm{C}_{18} \mathrm{H}_{32} \mathrm{O}_{2}$ & 20.689 & $327.09 \pm 13.6$ & $192.46 \pm 9.34$ & $134.22 \pm 6.19$ \\
\hline 10 & -Linolenic acid (GLA)(C18:3) & $\mathrm{C}_{18} \mathrm{H}_{30} \mathrm{O}_{2}$ & 21.859 & ND & ND & $0.58 \pm 0.01$ \\
\hline 11 & $\alpha$-Linolenic acid (ALA) (C18:3) & $\mathrm{C}_{18} \mathrm{H}_{30} \mathrm{O}_{2}$ & 22.685 & $4.51 \pm 1.09$ & $150.45 \pm 8.89$ & $170.59 \pm 9.63$ \\
\hline 12 & Eicosenoic acid (C20:1) & $\mathrm{C}_{20} \mathrm{H}_{38} \mathrm{O}_{2}$ & 23.553 & ND & $0.76 \pm 0.03$ & ND \\
\hline$\sum \mathrm{SPA}^{\mathrm{a}}$ & & & & 37.51 & 56.61 & 35.49 \\
\hline$\sum \mathrm{UFA}^{\mathrm{b}}$ & & & & 442.55 & 505.66 & 368.61 \\
\hline$\sum \mathrm{U} / \sum \mathrm{S}^{\mathrm{d}}$ & & & & 11.79 & 8.93 & 10.38 \\
\hline
\end{tabular}

Note: Data are expressed as mean values \pm standard deviations $(\mathrm{n}=3)$.

ND, under the detection limit; $\sum \mathrm{SPA}^{\mathrm{a}}$, Total saturated fatty acids; $\sum \mathrm{UFA}^{\mathrm{b}}$, Total unsaturated fatty acids; $\sum$ PUFA ${ }^{\mathrm{c}}$, The polyunsaturated fatty acids; $\sum \mathrm{U} / \sum \mathrm{S}^{\mathrm{d}}$, The ratio of unsaturated to saturated fatty acids; NTB, seed oil of Nitraria tangurorum B.; HRL, seed oil of Hippophae rhamnoides L.; BDM, seed oil of $B$. dasystachya $\mathrm{M}$. 
A critical feature of the berries obtained from the three plant species mentioned was the fact that all of them are edible. This property was particularly important in terms of food processing as any bioactive compounds in the berries do not have to be extracted to be useful in medical applications. Theoretically, the berries could simply be lyophilized to avoid perishing, and in an effort to ensure stability of any bioactive compounds they contain. Potential medical administration of these compounds could then take place in the form of dried berries. In addition, the TPC, TCC, TSC and the fatty acids of the three seed oils were significantly different. We hypothesize that the seed oil obtained from HRL (TPC $275.32 \pm 28.13 \mu \mathrm{g} / \mathrm{g}$; TCC $81.21 \pm 6.79 \mu \mathrm{g} / \mathrm{g}$; TSC 329.06 $\pm 16.53 \mu \mathrm{g} / \mathrm{g} ; \quad \sum$ PUFA $342.91 \mu \mathrm{g} / \mathrm{mL}$ ) was of superior quality compared to the others. Therefore, we surmised that the seed oil extracted from HRL could have superior pharmacodynamic effects as both an antioxidant and antifatigue agent. Therefore, we conducted the present study to test this hypothesis.
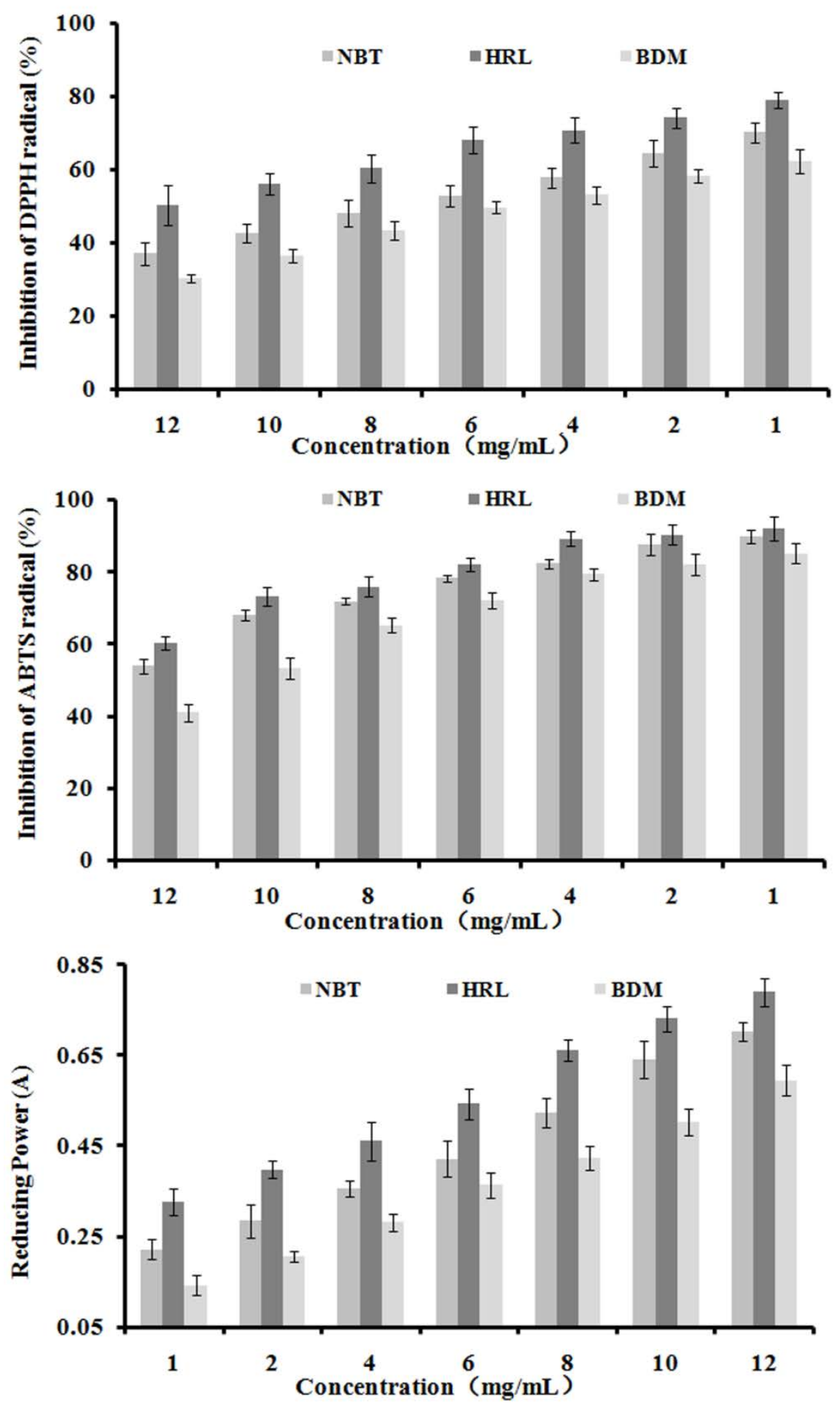

B

Figure 2. In vitro anti-oxidant activities of seed oils obtained from Nitraria tangurorum B. (NTB), Hippophae rhamnoides L. (HRL), and B. dasystachya M. (BDM). (A) DPPH radical scavenging activities; (B) ABTS radical scavenging activities; and (C) Reducing power. Data are expressed as mean values \pm standard deviations; $n=3$ in each concentration. Note: NTB, seed oil of Nitraria tangurorum B.; HRL, seed oil of Hippophae rhamnoides L.; BDM, seed oil of B. dasystachya M. 


\subsection{Anti-oxidant Activity in vitro}

The antioxidant activity of the seed oil obtained from the three berries was evaluated by conducting a DPPH radical-scavenging assay. DPPH is a stable free radical, commonly used as an effective reagent for the investigation of free radical scavenging in a variety of samples. DPPH exhibits a maximum absorption wavelength at $517 \mathrm{~nm}$, and changes colour from purple to yellow in the presence of anti-oxidants [25]. The scavenging activity of the three seed oils on the DPPH radical source is depicted in Figure 2 (A). Highly concentrated (12 mg/mL) seed oil from NBT, HRL and BDM inhibited $70.22 \pm 2.8 \%, 79.12 \pm 2.1 \%$ and $62.37 \pm$ $3.2 \%$ DPPH radicals, respectively. Presumably, the seed oil from the three berries acts as a hydrogen donor to convert DPPH to DPPH-H. The concentration of the sample that reduced radical absorbance by $50 \%$ (IC50) served as an index to compare antioxidant activity. A lower IC50 value indicates higher antioxidant activity. The result indicated that seed oils extracted from NBT, HRL and BDM were able to reduce the stable free radical $\mathrm{DPPH}$ to yellow coloured diphenylpicrylhydrazine with an IC50 of $3.536 \mathrm{mg} / \mathrm{mL}\left(\mathrm{R}^{2}=0.0 .9225\right), 1.180 \mathrm{mg} / \mathrm{mL}$ $\left(\mathrm{R}^{2}=0.9615\right)$ and $5.601 \mathrm{mg} / \mathrm{mL}\left(\mathrm{R}^{2}=0.9731\right)$, respectively. Moreover, the IC50 results indicated that the seed oil obtained from HRL proved to be significantly more active in scavenging DPPH radicals compared to the other seed oils obtained from NBT and BDM.

Another radical species, ABTS, has been used to measure the antioxidant activity of different substances in vitro. In general, antioxidant species donate electrons or hydrogen atoms to inactivate radical sources, in this case leading to ABTS discoloration [26]. This color reaction has been applied to quantify the total antioxidant activity of various substances used in a variety of different studies. As shown in Figure 2 (B), upon interaction with various concentrations of the seed oils from the berries, the absorbance of the $\mathrm{ABTS}^{+}$decreased in a dose-dependent manner. It was observed that the more concentrated the seed oil, the higher the percentage of scavenging ABTS radicals. Highly concentrated $(12 \mathrm{mg} / \mathrm{mL})$ seed oil from NBT, HRL and BDM inhibited $89.96 \pm 0.9 \%, 92.21 \pm$ $1.3 \%$ and $86.19 \pm 0.8 \%$ of ABTS radicals, respectively. The ABTS radical scavenging activity of NBT, HRL, and BDM also occurred in a dose dependent manner, with
IC50 values of $0.882 \mathrm{mg} / \mathrm{mL}\left(\mathrm{R}^{2}=0.9748\right), 0.606 \mathrm{mg} / \mathrm{mL}$ $\left(\mathrm{R}^{2}=0.9680\right)$ and $1.667 \mathrm{mg} / \mathrm{mL}\left(\mathrm{R}^{2}=0.9982\right)$, respectively. Therefore, the scavenging activity of the three seed oil upon addition of ABTS radicals followed the order: HRL $>$ NBT $>$ BDM.

The reducing power evaluates the ability to donate electrons and may therefore serve as an indicator of the potential antioxidant activity. The stronger the reducing power, the stronger the antioxidant activity. In the presence of antioxidants, in this assay the color changes from yellow to green or blue [38]. Figure 2 (C) showed the reducing power of various concentrations of seed oil. The reducing power of the seed oil from NBT, HRL and $\mathrm{BDM}$ increased at concentrations ranging from 0.182 to $0.703,0.242$ to 0.790 , and 0.104 to 0.596 , respectively. The results demonstrated that all these seed oils exhibited scavenging effects and had a positive correlation to their individual concentrations.

The present study confirmed our previous hypothesis of a superior activity of HRL compared to the other plant species. This sharp contrast might be attributed to the composition as well as the concentration of individual compounds present in oil, as well as different varieties of plant. Free radical theory strengthens the hypothesis that aging occurs by the accumulation of oxidative damage, such as DNA mutation, and lipid and protein dysfunction. Potentially, the seed oil obtained from HRL could prove to be more useful in the treatment of various ROS-related metabolic disorders. However, all three seed oils exhibited excellent antioxidant activity, such that they could find future application in medications designed to alleviate fatigue or mitigate oxidative damage of tissue in exercised stress conditions [39].

\subsection{Effects on Body Weight and Swimming Time}

The body weight of the mice was recorded after the experiment 7 days (initial), after 14 days (intermediate) and after 21 days (terminal). The changes in body weight during the experimental stage were listed in Table 3. Unfortunately, no significant differences in the body weight of mice could be observed in the three groups compared with the MC (model control) group during the initial, intermediate and terminal stages of the experiment $(p>0.05)$.

Table 3. Effects of seed oil on body weight of exhaustive swimming mice

\begin{tabular}{|c|c|c|c|c|}
\hline \multirow{2}{*}{ Group } & \multirow[t]{2}{*}{ Dose(mg/kg) } & \multicolumn{3}{|c|}{ Body weight(g) } \\
\hline & & Initial & Intermediate & Terminal \\
\hline NC & - & $20.49 \pm 0.34$ & $23.825 \pm 0.29$ & $26.94 \pm 0.17$ \\
\hline MC & & $20.48 \pm 0.35$ & $23.83 \pm 0.30$ & $26.94 \pm 0.28$ \\
\hline \multirow{3}{*}{ NTB } & 30 & $20.00 \pm 0.34$ & $24.60 \pm 0.27$ & $27.19 \pm 0.47$ \\
\hline & 60 & $20.16 \pm 0.29$ & $24.91 \pm 0.30$ & $28.62 \pm 0.70$ \\
\hline & 120 & $19.93 \pm 0.25$ & $24.72 \pm 0.24$ & $29.925 \pm 0.23$ \\
\hline \multirow[t]{3}{*}{ HRL } & 30 & $20.71 \pm 0.48$ & $24.90 \pm 0.41$ & $27.02 \pm 0.36$ \\
\hline & 60 & $20.42 \pm 0.44$ & $24.56 \pm 0.26$ & $28.67 \pm 0.28$ \\
\hline & 120 & $20.31 \pm 0.47$ & $27.41 \pm 0.48$ & $31.28 \pm 0.39^{\mathrm{a}}$ \\
\hline \multirow[t]{3}{*}{ BDM } & 30 & $19.78 \pm 0.35$ & $23.33 \pm 0.30$ & $27.18 \pm 0.23$ \\
\hline & 60 & $20.08 \pm 0.25$ & $23.04 \pm 0.21$ & $28.85 \pm 0.21$ \\
\hline & 120 & $21.95 \pm 0.31$ & $24.46 \pm 0.32$ & $30.67 \pm 0.33^{\mathrm{a}}$ \\
\hline
\end{tabular}

Note: Data are expressed as mean values \pm standard deviations. Statistical significance of mean (Forced swimming test with supplementation groups $v s$. model control group, ${ }^{\mathrm{a}} p<0.05$, ${ }^{\mathrm{b}} p<0.01$ ) was determined by the paired t-test. NC, the normal control group, $0.8 \%$ physiological saline, and were not subject to a swimming test; MC, the model control group, $0.8 \%$ physiological saline, and were subjected to a swimming test; NTB, Nitraria tangurorum B. seed oil group; HRL, Hippophae rhamnoides L. seed oil group; BDM, B. dasystachya M. seed oil group. 
The forced swimming test, one of the most commonly used animal models for the evaluation of the physical endurance capacity $[40,41]$, was selected to investigate any potential anti-fatigue effects of seed oil from the three berries. The overall duration of the swimming time to exhaustion provided quantification for the degree of fatigue [39]. Interestingly, our experimental results (Figure 3) indicated that a decrease in fatigue could be observed because seed oil could prolong swimming time after administration of seed oils for 21 days. However, the results also indicate that the swimming times for mice administrated with seed oil of HRL at a low dose (30 $\mathrm{mg} / \mathrm{kg}$ ) could not be significantly prolonged $(p>0.05)$.
Nevertheless, significant time increases could be observed upon administration of seed oil at a high dose $(120 \mathrm{mg} / \mathrm{kg}$, $p<0.01)$ and middle dose $(60 \mathrm{mg} / \mathrm{kg}, p<0.01)$ providing clear evidence for prolonged swimming times of treated mice. Furthermore, administration of seed oil from HRL at a high dose (14.00 $\pm 0.23 \mathrm{~min})$ exhibited the highest increase in prolonged swimming times; administration of seed oil from BDM at high dose $(12.07 \pm 0.55 \mathrm{~min})$ showed weaker effects than that of the seed oil from NTB (13.13 \pm $0.26 \mathrm{~min})$. Presumably, the time differences obtained might be due to the composition of the seed oil and varying concentrations of bioactive compounds in these three berries.

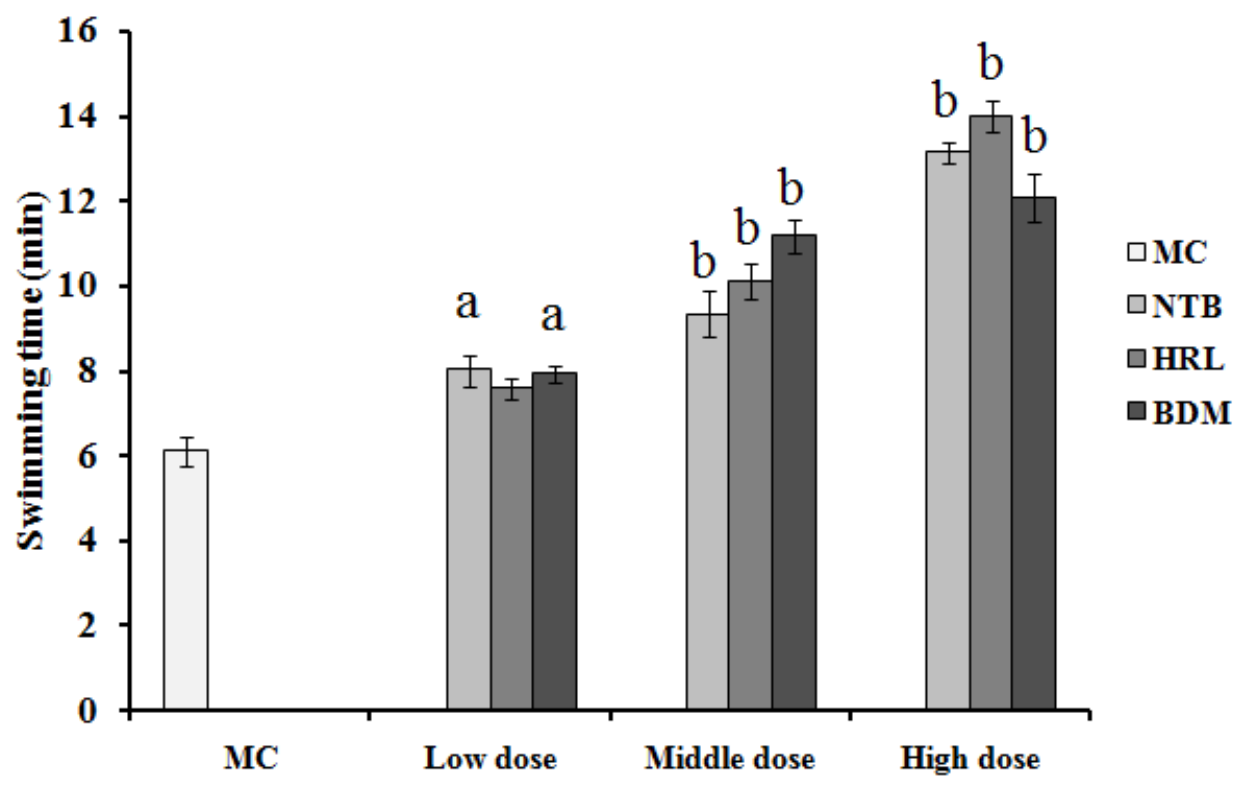

Figure 3. Effects of seed oil obtained from Nitraria tangurorum B. (NTB), Hippophae rhamnoides L. (HRL), and B. dasystachya M. (BDM) on the swimming time in exhaustive swimming mice

Note: The error bars represent one standard deviation.

Data are expressed as mean values \pm standard deviations. Statistical significance of mean (Forced swimming test with supplementation groups vs. model control group, ${ }^{\mathrm{a}} p<0.05,{ }^{\mathrm{b}} p<0.01$ ) was determined by the paired t-test. NC, the normal control group, $0.8 \%$ physiological saline, and were not subject to a swimming test; MC, the model control group, $0.8 \%$ physiological saline, and were subjected to a swimming test; NTB, Nitraria tangurorum B. seed oil group; HRL, Hippophae rhamnoides L. seed oil group; BDM, B. dasystachya M. seed oil group. High dose, seed oil of 120 mg/kg ; Middle dose, seed oil of $60 \mathrm{mg} / \mathrm{kg}$; Low dose, seed oil of $30 \mathrm{mg} / \mathrm{kg}$.

\subsection{Effects on Biochemical Serum Parameters}

Table 4 shows the effects of seed oil from the three berries on biochemical serum parameters of swimming mice. The group subjected to the FST (MC group) displayed increasing values in BUN, LC, LDH and CK levels and a decrease in serum GLU levels in comparison with the NC group. It became obvious that the effects of the three seed oil in the FST mice delayed the onset of any exercise-induced effects on biochemical parameters relevant for symptoms of fatigue. A higher blood glucose (GLU) value was an indication for higher glycogen utilization. That means that the increase in blood GLU demonstrated higher efficiency of the utilization of glycogen, which could improve exercise endurance and delay fatigue. Wang et al. [42] have reported that continuous exercise often led to hypoglycemia and could suppress the active functioning of the brain. Therefore, the amount of blood glucose could illustrate the speed and degree of fatigue development. As shown in Table 4, the GLU level of seed oil-treated groups increased significantly at middle $(60 \mathrm{mg} / \mathrm{kg})$ and high $(120 \mathrm{mg} / \mathrm{kg})$ doses compared to the MC group $(p<0.01)$. It was found that the level of GLU was much higher in all high dose $(120 \mathrm{mg} / \mathrm{kg})$ treatment groups compared to the model control group $(p<0.01)$, with ratio increases of 1.09 -fold (NBT), 1.15-fold (HRL) and 1.07-fold (BDM), respectively. Blood urea nitrogen (BUN) is a measure of the metabolism of protein and amino acids, which will drive a catabolic metabolism when the body cannot obtain enough energy though carbohydrate or lipid metabolism. A lower BUN concentration was indicative of decreased protein catabolism. Hence, urea nitrogen and exercise tolerance have a positive correlation [43]. As shown in Table 4, the content of BUN in the model group was $9.21 \pm 1.35 \mathrm{mmol} / \mathrm{L}$, and showed a significant increase compared to the normal group, which was $6.89 \pm 0.73$ $\mathrm{mmol} / \mathrm{L}$. Therefore, no significant difference could be found between the three berries. With an increasing dose administrated intragastrically, the BUN level in the serum of mice decreased significantly compared to the MC group ( $p$ <0.05), with clear dose-dependent effects observed among the seed oil-treated groups. In other words, the fact 
that BUN levels were decreased as a result of treatment with seed oils indicates a lower level of protein metabolism, which in turn may reflect an adaptation for exercise.

Table 4. Effects of seed oil on serum biochemical parameters of exhaustive swimming mice

\begin{tabular}{|c|c|c|c|c|c|c|}
\hline \multirow{2}{*}{ Group } & \multirow{2}{*}{$\begin{array}{l}\text { Dose } \\
(\mathrm{mg} / \mathrm{kg})\end{array}$} & \multicolumn{5}{|c|}{ Serum biochemical parameters } \\
\hline & & $\begin{array}{l}\text { GLU } \\
(\mathrm{mmol} / \mathrm{L})\end{array}$ & $\begin{array}{l}\mathrm{BUN} \\
(\mathrm{mmol} / \mathrm{L})\end{array}$ & $\begin{array}{l}\mathrm{LC} \\
(\mathrm{mmol} / \mathrm{L})\end{array}$ & $\begin{array}{l}\text { LDH } \\
\text { (U/gprot) }\end{array}$ & $\begin{array}{l}\text { CK } \\
\text { (U /gprot) }\end{array}$ \\
\hline MC & - & $5.45 \pm 0.98^{c}$ & $9.21 \pm 1.35^{c}$ & $24.32 \pm 3.22^{d}$ & $289.5 \pm 22.06^{d}$ & $2.75 \pm 0.21^{d}$ \\
\hline \multirow[t]{3}{*}{ NTB } & 30 & $9.50 \pm 1.35^{\mathrm{a}}$ & $7.34 \pm 0.63^{\mathrm{a}}$ & $21.33 \pm 3.04$ & $231.51 \pm 32.64^{\mathrm{a}}$ & $1.92 \pm 0.24^{\mathrm{a}}$ \\
\hline & 60 & $10.76 \pm 1.34^{b}$ & $6.15 \pm 0.70^{\mathrm{a}}$ & $19.16 \pm 2.29^{\mathrm{a}}$ & $194.87 \pm 27.30^{b}$ & $1.85 \pm 0.20^{b}$ \\
\hline & 120 & $11.41 \pm 1.67^{\mathrm{b}}$ & $6.06 \pm 0.79^{b}$ & $17.93 \pm 4.25^{b}$ & $168.46 \pm 22.69^{b}$ & $1.61 \pm 0.21^{\mathrm{b}}$ \\
\hline \multirow[t]{3}{*}{ HRL } & 30 & $10.88 \pm 1.49^{b}$ & $7.21 \pm 0.87^{\mathrm{a}}$ & $20.71 \pm 2.48$ & $210.77 \pm 35.36^{\mathrm{a}}$ & $1.72 \pm 0.22^{\mathrm{b}}$ \\
\hline & 60 & $11.08 \pm 1.63^{b}$ & $6.33 \pm 0.76^{b}$ & $18.42 \pm 2.44^{b}$ & $180.93 \pm 30.05^{b}$ & $1.52 \pm 0.21^{b}$ \\
\hline & 120 & $11.76 \pm 1.71^{\mathrm{b}}$ & $5.64 \pm 0.58^{b}$ & $16.31 \pm 3.47^{b}$ & $161.68 \pm 32.48^{\mathrm{b}}$ & $1.46 \pm 0.17^{\mathrm{b}}$ \\
\hline \multirow[t]{2}{*}{$\mathrm{BDM}$} & 30 & $8.92 \pm 1.73^{\mathrm{a}}$ & $7.58 \pm 0.96^{\mathrm{a}}$ & $21.95 \pm 2.31$ & $260.81 \pm 32.12^{\mathrm{a}}$ & $2.06 \pm 0.26^{\mathrm{a}}$ \\
\hline & 60 & $10.06 \pm 1.62^{b}$ & $6.93 \pm 0.87^{\mathrm{a}}$ & $19.68 \pm 4.25^{\mathrm{a}}$ & $201.01 \pm 25.41^{\mathrm{b}}$ & $1.87 \pm 0.28^{b}$ \\
\hline
\end{tabular}

Note: Data are expressed as mean values \pm standard deviations. Statistical significance of mean (Forced swimming test with supplementation groups vs. model control group, ${ }^{\mathrm{a}} p<0.05,{ }^{\mathrm{b}} p<0.01$ ) was determined by the paired t-test. Statistical significance of mean (Forced swimming test no supplementation group vs. normal control group, ${ }^{c} p<0.05$, ${ }^{d} p<0.01$ ) was determined by the paired t-test. GLU, glucose; BUN, blood urea nitrogen; LC, lactic acid; LDH, lactic dehydrogenase; CK, creatine phosphokinase; NC, the normal control group, $0.8 \%$ physiological saline, and were not subject to a swimming test; MC, the model control group, $0.8 \%$ physiological saline, and were subjected to a swimming test; NTB, Nitraria tangurorum B. seed oil group; HRL, Hippophae rhamnoides L. seed oil group; BDM, B. dasystachya M. seed oil group.

Muscles in general produce a considerable amount of lactic acid through metabolic reaction of lactate dehydrogenase when forced to perform an intense exercise regimen (or energy exhaustion). This increased concentration of lactic acid brings about a lowered $\mathrm{pH}$ inside the muscles, inducing signs of fatigue, and also driving many side effects of various biochemical and physiological processes that can be harmful to the body's performance [44]. Therefore, lactic acid (LC) is an indicator of the degree of fatigue after exercise and condition of recovery. It was found that the content of blood lactic acid was much lower in all high dose treatment groups compared to the model control group ( $p$ $<$ 0.01). The measurements were $26.27 \%$ (NBT), $32.93 \%$ (HRL) and $22.77 \%$ (BDM), respectively. Therefore, administration of seed oil from the three berries could effectively lower the blood lactic acid produced and postpone fatigue. Intensive exercise switches over to anaerobic metabolism; oxygen and pyruvic acid are consumed by lactic dehydrogenase (LDH) to lactic acid (LC). The increased LDH level would elevate the LC content, which would affect both the cardio-circulating and the skeletal muscle system [39]. As shown in Table 4, the level of $\mathrm{LDH}$ in the model group was significantly increased 1.07-fold compared with that in the normal group $(p<0.01)$. This effect was blocked by the administration of seed oils. The middle $(60 \mathrm{mg} / \mathrm{kg})$ and high dose $(120 \mathrm{mg} / \mathrm{kg})$ of seed oils reduced the LDH level in FST mice compared with the model group $(p<0.01)$. This result indicates that reduced levels of $\mathrm{LC}$ and $\mathrm{LDH}$ may be one way in which the seed oils exert their antifatigue effect.

A concentration increase of creatine phosphokinase $(\mathrm{CK})$ in blood serum indicates that necrosis of muscle cells and muscle damage has occurred or is occurring [43]. Therefore, the concentration of $\mathrm{CK}$ can also be used to as a biomarker of muscle fiber damage [45]. As shown in Table 4, the levels of CK increased significantly in the FST mice compared with normal mice $(p<0.01)$. However, the groups treated with seed oil showed a decreased release of serum $\mathrm{CK}$, in a dose-dependent manner $(p<0.05$ or $p<0.01)$. Moreover, all seed oils at a high dose $(120 \mathrm{mg} / \mathrm{kg})$ led to a significant reduction in the levels of serum CK when compared to the MC group ( $p$ $<0.01$ ).

Glycogen is the important source of energy during exercise and can supplement the consumption of blood glucose in order to maintain glucose in the physiologic range [46]. Energy is derived initially from the breakdown of glycogen in muscle during intense exercise, and at a later stage the energy will be derived from hepatic glycogen [47]. Hence, glycogen is a significant index in the process of fatigue. The effect of the seed oils from the three berries on glycogen content in hepatic (A) and muscle (B) are shown in Fig 4. The hepatic and muscle glycogen levels in middle and high dose of oils were much higher than that in the model group ( $p<0.05$ or $p$ $<0.01$ ). The liver glycogen (LG) content of NBT, HRL and BDM in high dose groups was significantly higher than that of the model group $(p<0.01)$, by 1.03 -fold, 1.19 -fold and 0.94 -fold, respectively. The muscle glycogen (MG) content of NBT, HRL and BDM in high dose groups was significantly higher than that of the model group ( $p<0.01$ ), by 1.01 -fold, 1.13 -fold and 0.82 -fold, respectively. These data indicate that seed oils from berries could improve the metabolic control of exercise and the activation of energy metabolism. However, there have been reports that plant extracts such as phenols, steroids, carotenoids and unsaturated fatty acids could be potent antioxidants, which could scavenge free radicals and therefore can act as a nutrient-dense source of energy to improve the extent of exercise [41, 48]. It has been shown that fatigue induces oxidative damage (lipid peroxidation) of the organs, resulting in abnormalities of glucose and lipid metabolism in the organic microenvironment [49]. Therefore, we propose that seed oils from the three berries may regulate or maintain glycogen levels by affecting antioxidant enzyme activity to recover normality of glucose metabolism [41]. 


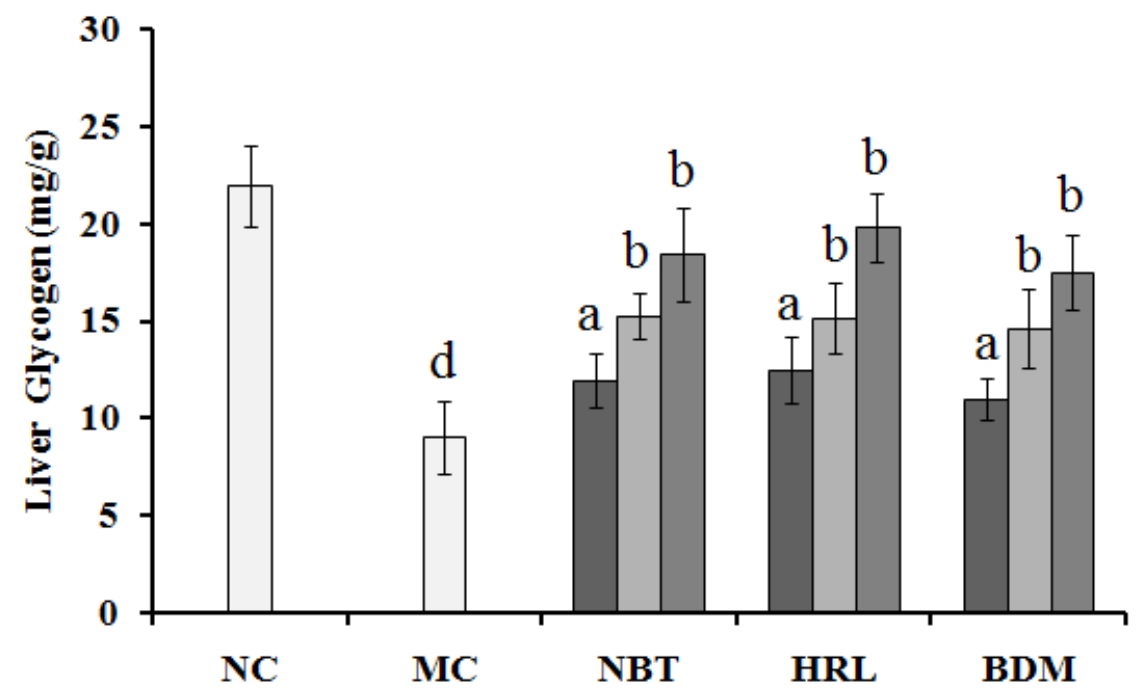

A

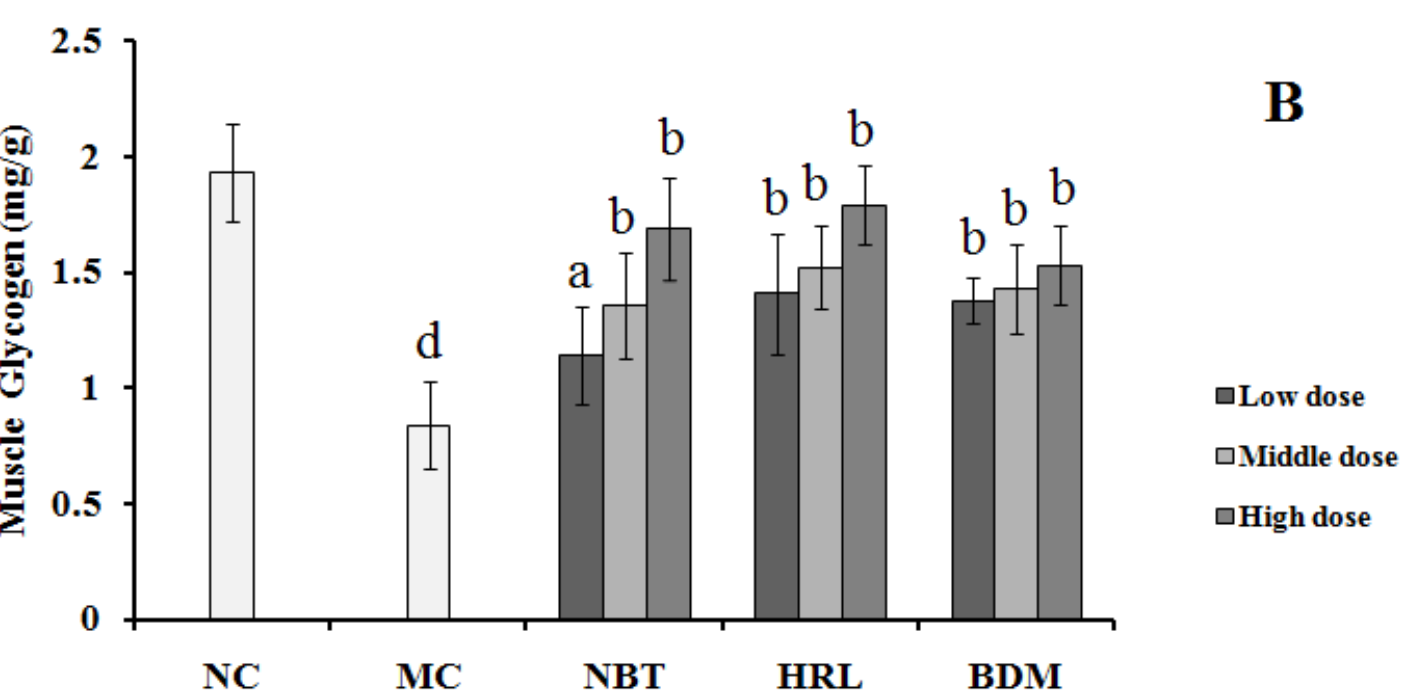

Figure 4. Effects of seed oil obtained from Nitraria tangurorum B. (NTB), Hippophae rhamnoides L. (HRL), and B. dasystachya M. (BDM) on the glycogen content of liver and muscle in exhaustive swimming mice. (A) Liver glycogen content. (B) Muscle glycogen content

Note: The error bars represent one standard deviation.

Data are expressed as mean values \pm standard deviations. Statistical significance of mean (Forced swimming test with supplementation groups vs. model control group, ${ }^{\mathrm{a}} p<0.05,{ }^{\mathrm{b}} p<0.01$ ) was determined by the paired t-test. Statistical significance of mean (Forced swimming test no supplementation group vs. normal control group, ${ }^{\mathrm{C}} p<0.05$, ${ }^{\mathrm{d}} p<0.01$ ) was determined by the paired t-test.NC, the normal control group, $0.8 \%$ physiological saline, and were not subject to a swimming test; MC, the model control group, $0.8 \%$ physiological saline, and were subjected to a swimming test; NTB, Nitraria tangurorum B. seed oil group; HRL, Hippophae rhamnoides L. seed oil group; BDM, B. dasystachya M. seed oil group. High dose, seed oil of 120 $\mathrm{mg} / \mathrm{kg}$; Middle dose, seed oil of $60 \mathrm{mg} / \mathrm{kg}$; Low dose, seed oil of $30 \mathrm{mg} / \mathrm{kg}$.

These results obtained indicate that intragastric administration of seed oils from the three berries could help mice establish a suitable glycogen metabolism with sufficient energy supply (LG and MG), as well as reduce protein metabolism to decrease side effects of the intense exercise regimen. If translatable to humans, such effects might be advantageous in delaying symptoms of fatigue. However, further studies of all the bioactive compounds involved are required in order to clearly identify the biological mechanism driving improved energy mobilization.

of enzymes involved in such mechanisms include superoxide dismutase (SOD), glutathione peroxidase (GSH-Px) and catalase (CAT) [6]. The presence of antioxidant enzymes is detected, due to an increase in the concentration of free radicals inside the muscle cells as exercise takes place. Previous results published by $\mathrm{Yu}$ et al. [50] further confirmed that ingestion of exogenous anti-oxidants would led to a decrease of exercise-induced oxidative stress, while improving the overall physiological conditions. You et al. [40] reported that oxidative stress could significantly affect the etiology of chronic fatigue syndrome and that antioxidants might be a possible

\subsection{Effects on the Activity of Anti-oxidant Enzyme}

The effects of seed oil on the enzymatic antioxidant activities in mice are listed in Table 5. Muscle cells in general exhibit complex endogenous cell defense mechanisms to eliminate reactive oxygen species. Classes treatment. Superoxide dismutase (SOD) can catalyse the transformation of superoxide radicals to $\mathrm{H}_{2} \mathrm{O}_{2}$ which plays an important role in defense against superoxide radicals. Glutathione peroxidase (GSH-Px) is a protective enzyme as it can decompose $\mathrm{H}_{2} \mathrm{O}_{2}$ and lipid peroxides. Catalase (CAT) can catalyze the $\mathrm{H}_{2} \mathrm{O}_{2}$ to form water and $\mathrm{O}_{2}$ [51]. Our study showed that the levels of SOD, GSH-Px, and 
CAT were increased among these seed oil-treated groups and administration doses of middle $(60 \mathrm{mg} / \mathrm{kg})$ and high $(120 \mathrm{mg} / \mathrm{kg}$ ) showed significant changes compared to the MC group ( $p<0.01)$, which were also dose-dependent.

Malonic dialdehyde (MDA) is the product of oxidation of polyunsaturated fatty acids. MDA has frequently been used as an indicator of oxidative stress in response to exercise [52]. Further analysis of the MDA level, is conducted as a quantitative indicator of lipid pre-oxidation. The MDA levels were significantly decreased in seed oil administrated mice compared with the MC group ( $p<$ 0.05). The MDA content in the muscle of the NBT, HRL and BDM at high dose groups was significantly lower ( $p$ $<0.01$ ) than in that of the MC group, by $43.38 \%, 54.83 \%$ and $41.94 \%$, respectively. Furthermore, the levels of antioxidant in the HRL group were superior to the levels of the other seed oil-treated groups. However, the three antioxidant enzymes of the BDM group at middle (60 $\mathrm{mg} / \mathrm{kg})$ and high $(120 \mathrm{mg} / \mathrm{kg})$ doses did not increase in comparison to each other.

Table 5. Effects of seed oil on muscle antioxidant parameters of exhaustive swimming mice

\begin{tabular}{|c|c|c|c|c|c|}
\hline \multirow{2}{*}{ Group } & \multirow[t]{2}{*}{ Dose (mg /kg) } & \multicolumn{4}{|c|}{ Antioxidant parameters } \\
\hline & & SOD(U/mgprot) & GSH-Px(U/mgprot) & CAT(U/mgprot) & MDA(nmol/mgprot) \\
\hline NC & - & $356.73 \pm 10.11$ & $216.45 \pm 11.45$ & $340.32 \pm 42.54$ & $1.54 \pm 0.13$ \\
\hline MC & & $301.22 \pm 7.09$ & $195.03 \pm 17.42^{c}$ & $260.06 \pm 25.00^{c}$ & $3.72 \pm 0.22^{d}$ \\
\hline \multirow[t]{3}{*}{ NTB } & 30 & $478.20 \pm 8.91^{\mathrm{b}}$ & $220.23 \pm 9.15^{\mathrm{a}}$ & $377.34 \pm 27.17^{\mathrm{a}}$ & $2.81 \pm 0.23^{\mathrm{a}}$ \\
\hline & 60 & $519.67 \pm 11.37^{b}$ & $281.45 \pm 9.09^{b}$ & $438.27 \pm 24.78^{b}$ & $2.17 \pm 0.37^{b}$ \\
\hline & 120 & $568.33 \pm 10.06^{b}$ & $321.69 \pm 12.13^{b}$ & $536.67 \pm 37.08^{b}$ & $1.92 \pm 0.22^{\mathrm{b}}$ \\
\hline \multirow[t]{3}{*}{ HRL } & 30 & $491.23 \pm 9.17^{\mathrm{b}}$ & $253.14 \pm 8.18^{\mathrm{b}}$ & $527.70 \pm 25.96^{b}$ & $2.36 \pm 0.19^{\mathrm{a}}$ \\
\hline & 60 & $530.48 \pm 22.37^{b}$ & $274.53 \pm 4.33^{b}$ & $556.96 \pm 29.62^{b}$ & $1.87 \pm 0.25^{\mathrm{b}}$ \\
\hline & 120 & $587.12 \pm 4.03^{b}$ & $298.04 \pm 15.94^{b}$ & $647.14 \pm 20.89^{b}$ & $1.68 \pm 0.42^{b}$ \\
\hline \multirow[t]{3}{*}{ BDM } & 30 & $439.91 \pm 11.77^{\mathrm{a}}$ & $216.58 \pm 6.10^{\mathrm{a}}$ & $325.17 \pm 10.72^{\mathrm{a}}$ & $2.98 \pm 0.11$ \\
\hline & 60 & $501.78 \pm 9.03^{b}$ & $272.41 \pm 4.54^{\mathrm{b}}$ & $457.23 \pm 27.23^{b}$ & $2.34 \pm 0.32^{\mathrm{a}}$ \\
\hline & 120 & $527.32 \pm 8.14^{b}$ & $284.81 \pm 6.38^{b}$ & $526.54 \pm 38.31^{b}$ & $2.16 \pm 0.43^{b}$ \\
\hline
\end{tabular}

Note: Data are expressed as mean values \pm standard deviations. Statistical significance of mean (Forced swimming test with supplementation groups vs. model control group, ${ }^{\mathrm{a}} p<0.05,{ }^{\mathrm{b}} p<0.01$ ) was determined by the paired t-test. Statistical significance of mean (Forced swimming test no supplementation group vs. normal control group, ${ }^{\mathrm{c}} p<0.05,{ }^{\mathrm{d}} p<0.01$ ) was determined by the paired t-test. MDA, malonic dialdehyde; SOD, superoxide dismutase; GSH-Px, glutathione peroxidase; CAT, catalase; NC, the normal control group, $0.8 \%$ physiological saline, and were not subject to a swimming test; MC, the model control group, $0.8 \%$ physiological saline, and were subjected to a swimming test; NTB, Nitraria tangurorum B. seed oil group; HRL, Hippophae rhamnoides L. seed oil group; BDM, B. dasystachya $\mathrm{M}$. seed oil group.

These data indicate that seed oils from the three berries administered by intragastric administration could support the ROS-defense mechanisms in mice, by modulating antioxidant parameters and could extend the performance time frame during intense exercise. Such findings could explain protection mechanisms of the corpuscular membrane, in an effort to prevent lipid oxidation via elevated enzyme activities in forced swimming mice. However, in this study, we did not obtain sufficient data to pinpoint the relevant compounds in the seed oils responsible for the effects observed. Further detailed studies will be required to identify the individual compounds and are currently underway in our lab.

\section{Conclusions}

In conclusion, the seed oils extracted from Nitraria tangurorum B., Hippophae rhamnoides $L$. and $B$. dasystachya $\mathrm{M}$. proved to be rich in antioxidant compounds such as polyphenols, carotenoids, steroids and polyunsaturated fatty acids. Our study suggested that the seed oils extracted from the three berries could provide different antioxidant and anti-fatigue activities. Specifically, the effects on ROS were encouraging, and are certainly due to several different compounds found within the seed oils of the three berries. Further investigations will be necessary in order to identify individual compounds and the corresponding effects. Overall, our study suggested that the seeds and seed oils extracted from the three berries could provide an inexpensive raw material for the development of natural antioxidant food additives, as well as health products.

Furthermore, the results presented here offer further incentives to develop pharmaceutical compounds with antioxidant activity and/or bioactive compounds against symptoms of anti-fatigue.

\section{Acknowledgment}

The authors are grateful to the Foundation of International S\&T cooperation program of China (No.S2014GR0058) for financial support of this work.

\section{Statement of Competing Interests}

The authors have no competing interests.

\section{A List of Non-standard Abbreviations}

NTB: Nitraria tangurorum B., HRL: Hippophae rhamnoides L., BDM: Berberis dasystachya M., TPC: total polyphenol content, TCC: total carotenoid conten, TSC: total steroids content, DPPH: 2,2-diphenyl-1picrylhydrazyl radical, ABTS: 2, 2-azino-bis (3ethylbenzothiazoline-6-sulfonic acid) diammonium, FST: Forced swim test, NC: the normal control group , MC: the model control group, GLU: glucose, LC: lactic acid, BUN: blood urea nitrogen, LDH: lactic dehydrogenase, CK: creatine phosphokinase, LG: liver glycogen, MG: muscle glycogen, MDA: malondialdehyde, SOD: superoxide dismutase, GSH-Px: glutathione peroxidase, CAT: catalase. 


\section{References}

[1] Zhang, Y. and Wang, B. "Effects of polysaccharides from Cordycepssinensis mycelium on physical fatigue in mice." Bangladesh J Pharmaco, 7. 217-221. 2012.

[2] Tanaka, M., Mizuno, K., Fukuda, S., Shigihara, Y. and Watanabe, Y. "Relationships between dietary habits and the prevalence of fatigue in medical students." Nutrition, 24. 985-989. 2008.

[3] Zhang, X.L., Ren, F., Huang, W., Ding, R. T., Zhou, Q. S. and Liu, $\mathrm{X}$. W. "Anti-fatigue activity of extracts of stem bark from Acanthopanax senticosus.” Molecules, 16. 28-37. 2010.

[4] Pedersen, T.H., Nielsen, O.B., Lamb, G.D. and Stephenson, D.G. "Intracellular acidosis enhances the excitability of working muscle.” Science, 305. 1144-1147. 2004.

[5] Blokhina, O., Virolainen, E. and Fagerstedt, K.V. "Antioxidants, oxidative damage and oxygen deprivation stress: a review." Ann Bot, 91. 179-184. 2003.

[6] Bing, Y. and Zhao, B.W. "Effects of Ginkgo biloba extract on free radical metabolism of liver in mice during endurance exercise." Afr J Tradit Complement Altern Med, 7. 291-295. 2010.

[7] Wang, B.X., Cui, J.C., Liu, A.J. and Wu, S.K. "Studies on the anti-fatigue effect of the saponins of stems and leaves of panax ginseng (SSLG).” J. Tradit. Chin.Med., 3. 89-94. 1983.

[8] Appleton, K.M., Rogers, P.J. and Ness, A.R. "Is there a role for n3 long-chain polyunsaturated fatty acids in the regulation of mood and behaviour? A review of the evidence to date from epidemiological studies, clinical studies and intervention trials.” Nutr Res Rev ., 21. 13-41. 2008.

[9] Puri, B.K., Holmes, J. and Hamilton, G. "Eicosapentaenoic acidrich essential fatty acid supplementation in chronic fatigue syndrome associated with symptom remission and structural brain changes.” Int J Clin Pract, 58. 297-299. 2004.

[10] Northwest Institute of Plateau Biology, Chinese Academy of Sciences, Qinhai economic Flora, Qinhai People’s Press, Xining: 1987.

[11] Ji, L.J. "The analysis of free amino acid and ascorbic acid in Sea buckthorn, Tanguticus white thorn, yellow thorn.” Chine Bul of Bot, 6. 487-488. 1989.

[12] Gong, Z.Q., Zhang, L., Shi, W.Y. and Liu, P.L. "The analysis of mechanisms of facial skin aging treated by three thorn cream." Journal of Qinghai Medical College, 2. 55-59. 1988.

[13] Ma, L., Chablat, D., Bennis, F., Zhang, W., Hu, B. and Guillaume, F. "Fatigue evaluation in maintenance and assembly operations by digital human simulation in virtual environment." Virtual Reality, 15. 55-68. 2011.

[14] Ma, T.J. and Xu Y.Q. "The anti-fatigue effect of Nitraria seed oil on mice." Acta Laboratorium Animalis Scientia Sinica, 5. 77-79. 2012.

[15] Jiao, Y., Wang, Z.Y., Liu, Y. and Zhang R. "The anti-fatigue effect of compound Sea buckthorn liquid in mice." Acta Nutrimenta Sinica. 3. 29-32. 2009.

[16] Zhang, F.P., Zhao, Y., Liu, Y.M. and Suo, Y.R. "Comparative study on chemical constituents in seed oils of Nitraria, Seabuckthorn and Wolf-berry in Qinghai-Tibetan Plateau." Nat Prod Res Dev, 8. 16-20. 2010.

[17] Savoire, R., Lanoisellé, J.-L., Vorobiev, E. "Mechanical continuous oilexpression from oilseeds: a review." Food Bioprocess Technol. 6. 1-16. 2013.

[18] Ni W.H., Gao T.T., Wang H.L., Du Y.Z., Li J.Y., Li C., Wei l.x., Bi H.T. "Anti-fatigue activity of polysaccharides from the fruits of four Tibetan plateau indigenous medicinal plants." $J$. Ethnopharmacol. 150. 529-535. 2013.

[19] Rombaut, N., Savoire, R., Thomasset, B., Castello, J., Van Hecke, E. and Lanoisellé, J. L. "Optimization of oil yield and oil total phenolic content during grape seed cold screw pressing." Ind. Crops Prod, 63. 26-33. 2015.

[20] Maier, T., Schieber, A., Kammerer, D.R. and Carle, R. "Residues of grape (Vitis viniferaL.) seed oil production as a valuable source of phenolic antioxidants.” Food Chem, 112. 551-559. 2009.

[21] Orthofer, R. and Lamuela-Raventos, R.M. "Analysis of total phenols and other oxidation substrates and antioxidants by means of Folin-Ciocalteu, s reagent.” Method Enzy. Mol., 299. 152-178. 1999.

[22] Ilyasoğlu,H. "Characterization of rosehip (Rosa canina L.) seed and seed oil.” Int J. Food Prop.,17. 1591-1598. 2014.
[23] Li, Y.H., Li, H.L., Tan, Y.F. and Zhang, J.Q. "Determination of total steroids in Carica papaya LINN seed by spectorphotometry." Journal of Hainan Medical, 9. 1223-1225. 2012.

[24] Fu, H., Wang, Q., Zhou, Z.Y.,Zheng, S.Z. and Meng, J.C. "Analysis of fatty acids of seed oil of Microula sikkimensis in Tianzhu by GC/MS.” Acta Agrestia Sin, 5. 206-208. 1997.

[25] Lin, K.H., Ye, S.Y., Lin, M.Y., Shi, M.C., Yang, K.T. and Hwang, S.Y. "Major chemotypes and antioxidative activity of the leaf essential oils of Cinnamomum osmophloeum Kaneh. from a clonal orchard." Food Chem, 105. 133-139. 2007.

[26] Díaz-Reinoso, B., Moure, A., Domianguez, H. and Parajoa, J.C. "Supercritical $\mathrm{CO}_{2}$ extraction and purification of compounds with antioxidant activity.” J Agric Food Chem, 54. 2441-2469. 2006.

[27] Ferreira, I.C., Baptista, P., Vilas-Boas, M. and Lillian, B. Free radical scavenging capacity and reducing power of wild edible mushrooms from northeast Portugal: individual cap and stipe activity. Food Chem,100, 1511-1516. 2007.

[28] World Health Organization "Principles of laboratory animal care." WHO Chronicle, 39. 51-56. 1985.

[29] Porsolt, R.D., Anton, G., Blavet, N. and Jalfre, M. "Behavioral despair in rats: a new model sensitive to anti-depress and treatments.” Eur J. Pharmacol, 47. 379 -391. 1978.

[30] Yu, F., Gao, J., Zeng, Y. and Liu, C.X. "Effects of adlay seed oil on blood lipids and antioxidant capacity in hyperlipidemic rats." $J$ Sci Food Agric, 91. 1843-1848. 2011.

[31] Siger, A., Nogala-Kalucka, M. and Lampart-Szczapa, E. “The content and anti-oxidant activity of phenolic compounds in coldpressed plant oils.” J. Food Lipids, 15. 137-149. 2008.

[32] Gorinstein, S., Park, Y.S., Heo, B.G., Namiesnik, J., Leontowica, H., Leontowica, M., Ham, K.S., Cho, J.Y. and Kang, S.G. "A comparative study of phenolic compounds and antioxidant and antiproliferative activities in frequently consumed raw vegetables.” Eur Food Res Technol., 228. 903-911. 2009.

[33] Fan, L.D., Zhai, F., Shi, D.X., Qiao, X.F., Fu, X.L. and Li, H.P. "Evaluation of antioxidant properties and anti- fatigue effect of green tea polyphenols.” Scientific Research and Essays., 6. 26242629. 2011.

[34] Ishida, B.K. and Chapman, M.H. "A comparison of carotenoid content and total antioxidant activity in catsup from several commercial sources in the United States.” J. Agric Food Chem, 52. 8017-8020. 2004.

[35] Lyder, D.L., Sonia, R.P., Winston, F.T., Suzanne, M.B. and Wilson, F.R. "Minor cassane diterpenoids of Caesalpinia bonduc." J Nat Prod, 61. 1462-1465. 1998.

[36] Orhann, I.E., Ozcelik, B. and Sener, B. "Evaluation of antibacterial, antifungal, antiviral, and antioxidant potentials of some edible oils and their fatty acid profiles.” Turk J Biol, 35. 251-258. 2011.

[37] Connor, W.E. " $\alpha$-Linolenic acid in health and disease.” Am J. Clin Nutr, 69. 827 -828. 1999.

[38] Ahmadi, F., Sadeghi, S., Modarresi, M., Abiri, R. and Mikaeli, A. "Chemical composition, in vitro anti-microbial, antifungal and antioxidant activities of the essential oil and methanolic extract of Hymenocrater longiflorus Benth. of Iran.” Food Chem Toxicol, 48 1137-1144. 2010.

[39] Huang, C.C., Hsu, M.C., Huang, W.C., Yang, H.R. and Hou, C.C. "Triterpenoid-rich extract from antrodia camphorata improves physical fatigue and exercise performance in mice.” Evid Based Complement Alternat Med, 2012.1-8. 2012.

[40] You, L., Zhao, M., Regenstein, J.M. and Ren, J. "In vitro antioxidant activity and in vivo antifatigue effect of loach (Misgurnus anguillicaudatus) peptides prepared by papain digestion.” J. Food Chem, 1.188-194. 2011.

[41] Kuo, Y.H., Tsai, W.J., Loke, S.H., Wu, T.S. and Chiou, W.F. "Astragalus membranaceus flavonoids (AMF) ameliorate chronic fatigue syndrome induced by food intake restriction plus forced swimming." J. Ethnopharmacology, 122. 28 -34. 2009.

[42] Wang, J.J., Shieh, M.J., Kuo, S.L., Lee, C.L. and Pan, T.M. "Effect of red mold rice on antifatigue and exercise-related changes in lipid peroxidation in endurance exercise." Appl Microbiol Biotechnol., 70. 247-253. 2006.

[43] Shan, L.N., and Shi, Y.X. "Effects of Polysaccharides from Gynostemma Pentaphyllum (Thunb.), Makino on Physical Fatigue.” Afr. J. Tradit. Complement. Altern. Med., 11. 112-117. 2014.

[44] Jiang, D.Q., Guo, Y., Xu, D.H., Huang, Y.S., Yuan, K. and Lv, Z.Q. "Antioxidant and anti-fatigue effects of anthocyanins of mulberry juice purification (MJP) and mulberry marc purification 
(MMP) from different varieties mulberry fruit in China." J. Food Chem. Toxicol, 59. 1-7. 2013

[45] Ding, X.Q., Tang, K.J., Lu, P.J. and Putheti, R. "Antifatigue effects of polydatin from Chinese herb Polygonum cuspidatum in swimming mice.” Afr J Microbiol Res, 3. 358-361. 2009.

[46] Jung, K.A., Han, D., Kwon, E.K., Lee, C.H. and Kim, Y.E. "Antifatigue effect of Rubbus coreanus Miquel extract in mice." Journal of Medicinal Food, 10(4). 689-693. 2007.

[47] Anand, T., Phani Kumar, G., Pandareesh, M.D., Swamy, M.S., Khanum, F. and Bawa, A.S. "Effect of bacoside extract from Bacopa monniera on physical fatigue induced by forced swimming.” Phytother Res, 26. 587-593. 2012.

[48] Matkowski, A., Jamiołkowska-Kozlowska, W. and Nawrot, I. "Chinese medicinal herbs as source of antioxidant compounds- where tradition meets the future." Curr. Med. Chem., 20. 9841004. 2013

[49] Radak, Z., Chung, H.Y., Koltai, E., Taylor, A.W. and Goto, S. "Exercise, oxidative stress and hormesis." Ageing Res. Rev., 7. 3442. 2008.

[50] Yu, F., Lu, S.Q., Yu, F.H., Feng, S.T. , Li, R.D. and Wang, R. "Protective effects of polysaccharide from Euphorbia kansui (Euphorbiaceae) on the swimming exercise-induced oxidative stress in mice.” Can. J. Physiol. Pharmacol, 84. 1071-1079. 2006.

[51] Powers, S.K. and Lennon, S.L. "Analysis of cellular response to free radicals: focus on exercise and skeletal muscle." Proc Nutr Soc, 58. 1025-1033. 1999.

[52] Rajguru, S.U., Yeargans, G.S. and Seidler, N.W. "Exercise causes oxidative damage to rat skeletal muscle microsomes while increasing cellular sulfhydryls.” Life Sci, 54. 49-157. 1994. 